\title{
Familial polyposis coli associated with extracolonic abnormalities
}

T. G. PARKS, H. J. R. BUSSEY, AND H. E. LOCKHART-MUMMERY

From St. Mark's Hospital, London

SUMMARY The pedigree of a polyposis coli family, in which several individuals had extracolonic abnormalities associated with the condition, is presented. Some of the problems encountered in management are discussed. The literature is reviewed and a simple classification of the extracolonic abnormalities is suggested.

The first description of adenomatous polyposis (familial polyposis coli) is probably that of Chargelaigne (1859) but the hereditary nature of the disease was not recognized until 1882 when Harrison Cripps reported the presence of the disease in a brother and sister. The frequent association with intestinal cancer was mentioned first by Handford (1890) and during the next 30 years both the precancerous nature and the hereditary character of the disease had become firmly established. An association of polyposis with subcutaneous tumours was first noted by Devic and Bussy (1912) but it was not until 1953 that Gardner and Richards reported the syndrome now known generally as Gardner's syndrome. They investigated a family in which seven members were suffering from a combination of lesions consisting of (a) multiple adenomas of the large intestine, (b) multiple osteomas of the skull and mandible, and (c) multiple epidermoid cysts and soft tissue tumours of the skin. This family has been followed up and further reported by Gardner (1962). Since the original paper there has arisen a considerable bibliography of the syndrome which now includes reports of similar cases but with a number of associated lesions other than those mentioned in the triad and whose connexion with the syndrome has yet to be established.

It is the purpose of this paper to describe a family, members of which have not only polyposis coli but also some usual and some unusual features of Gardner's syndrome, and to discuss the unexpected difficulties encountered in the management of the disease in these patients.

\section{Family History}

The pedigree of the family, which first came under observation at St. Mark's Hospital in 1953, is shown in Figure 1. The family consists of 46 individuals, of whom 15 are considered to have polyposis. In three of these (I 2, I 3, I 4) the only information available is that they died of intestinal cancer at the ages of 49, 51, and 49 years. Another member (II 4) is known to have had polyposis and intestinal cancer from which he died aged 33 years. The two children of I 2 emigrated to Canada where both underwent colectomy for benign polyposis around the age of 45 years (II 1 and II 2). One of these two patients had a son (III 1) who developed multiple adenomas at the age of 14 years but died from a brain tumour two years later and is a possible example of Turcot's syndrome.

The remaining eight patients with polyposis comprise the group treated at St. Mark's Hospital. Four of them (III 2, III 3, III 6, and III 10) have just begun to develop adenomas and have, so far, received no surgical treatment. The remaining four patients (II 7, II 8, II 9 and III 9) 

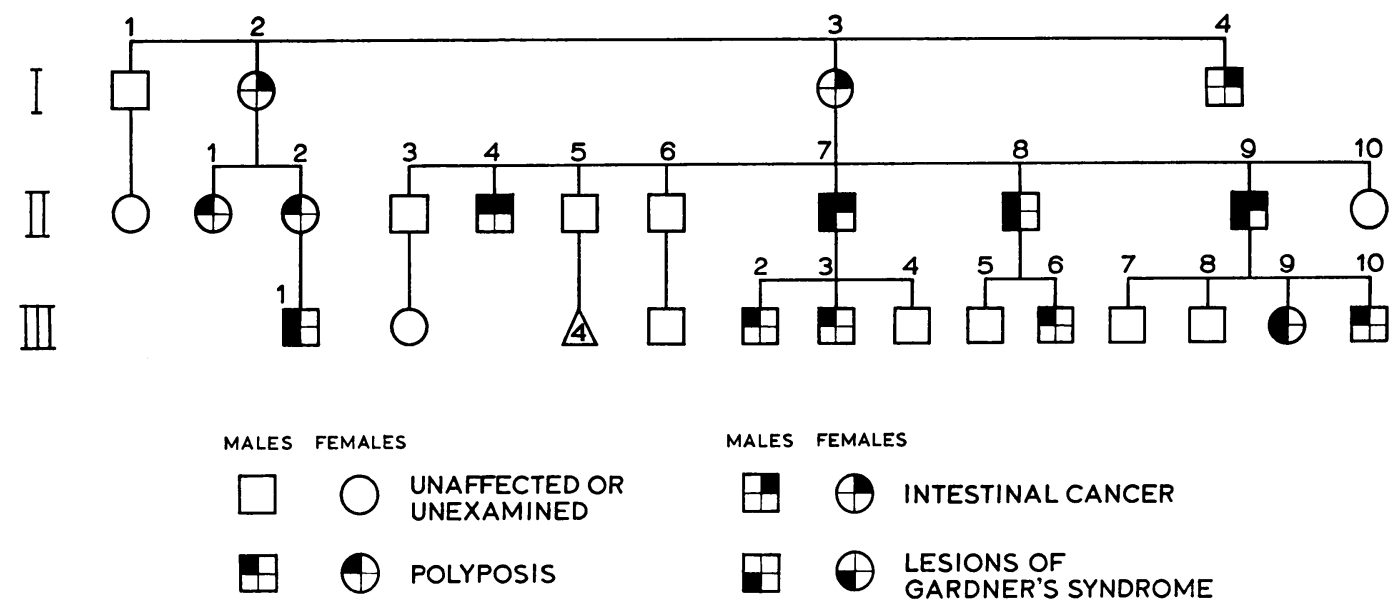

Fig. 1 The pedigree of the polyposis family

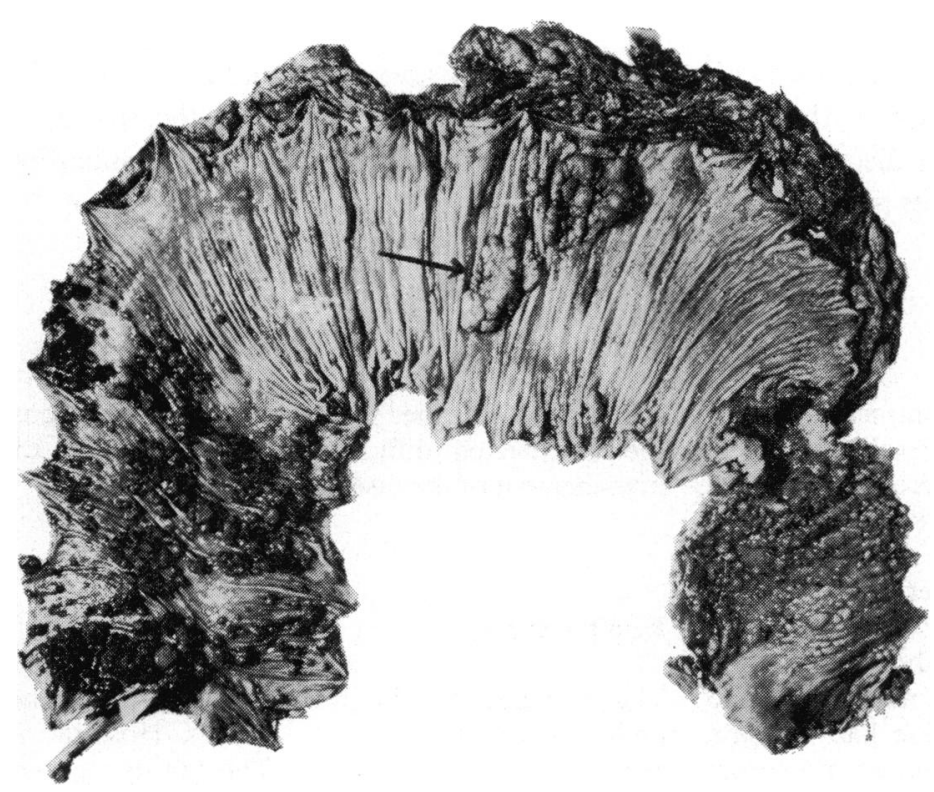

he was admitted to hospital elsewhere with a four-year history of diarrhoea and the passage $\vec{\varphi}$ of bright red blood per rectum. He was found to have multiple polypi in the rectum and an abdominoperineal excision of the rectum was performed with the establishment of a left iliac colostomy. Thereafter, he remained well until 1963, when he developed a polyp on the colostomy stoma; this was trimmed.

In December 1965 he had an episode of $\overline{\bar{o}}$ subacute intestinal obstruction, and another in April 1966, and after conservative management in another hospital, he was referred to St. Mark's where he was first seen and admitted on 13 April 1966.

On examination there were signs of subacute intestinal obstruction. In addition, he had an $\delta$ osteoma ( $2 \mathrm{~cm}$ in diameter) on the left frontal region and sebaceous cysts on the left wrist and $ᄋ$ right forearm. Three sebaceous cysts had been removed from the scalp 10 years previously.

Barium enema via the colostomy revealed an

Fig. 2 The colectomy specimen of case 1 showing an annular carcinoma of the splenic flexure and flat papillary adenoma with a focus of adencarcinoma of the transverse colon in addition to multiple adenomata.

form the basis of this study and their case histories are given below.

\section{Case Histories}

CASE 1

V.P. (II 9), born on 11 November 1918, was first seen at St. Mark's on 13 April 1966. His previous history was that at the age of 29 years annular carcinoma of the splenic flexure and an irregular polyp ( $2 \mathrm{~cm}$ in diameter) in the proximal $\mathrm{N}$ transverse colon was also considered suspicious of malignancy. The rest of the colon was studded $\sigma$ with innumerable polypi up to $1 \mathrm{~cm}$ in diameter.

At operation on 22 April the presence of a constricting carcinoma at the splenic flexure was $\stackrel{\mathscr{\rho}}{+}$ confirmed, in addition to multiple polypi through- 7 out the remainder of the colon. No hepatic $\frac{\vec{D}}{\Phi}$ metastases were found. Colectomy and ileostomy $\cong$ was performed and the postoperative course was $\mathscr{Q}$ uneventful.

Pathology (first specimen)

The colectomy specimen (Fig. 2) contained about 550 adenomatous tumours and two definitely malignant growths were also present. One of these was a flat papillary adenoma with a focus of adenocarcinoma of an average grade 


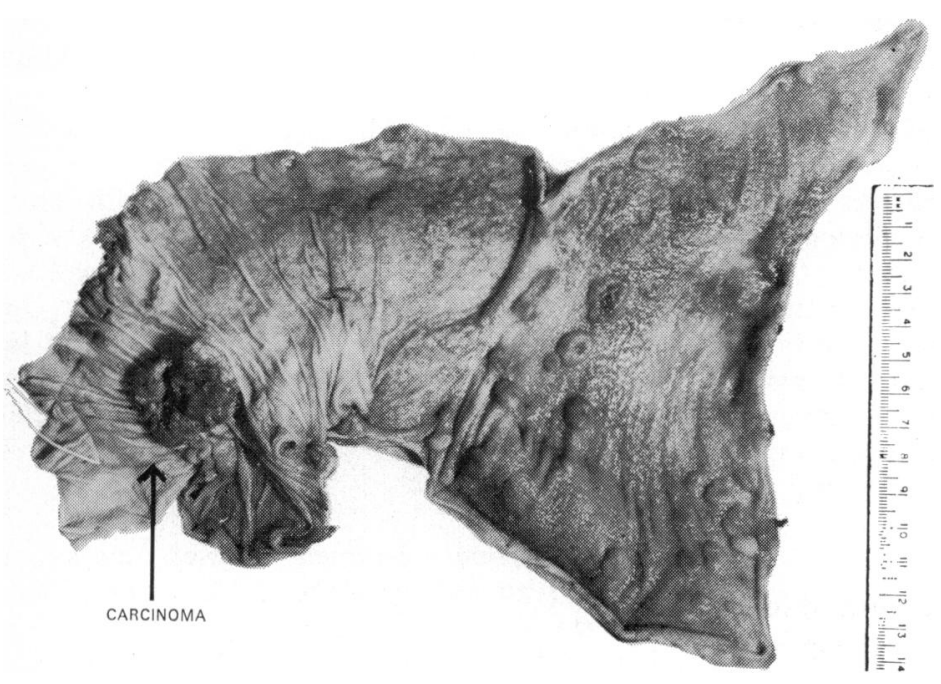

Fig. 3 The pancreatic-duodenectomy specimen of case 1 showing a papillary adenocarcinoma involving the ampulla of Vater. Numerous sessile tumours, particularly of the pyloric end of the stomach, had histological features of a hamartomatous nature.

of malignancy limited to the muscle coat in the transverse colon. The second carcinoma was a deeply ulcerated tumour, $5.5 \mathrm{~cm}$ in diameter, at the splenic flexure. This had spread extensively in the pericolic fat and two lymphatic metastases were present in 28 regional nodes examined (C 1 case).

The patient was seen at four-monthly intervals and in the year after the colectomy gained $1 \frac{1}{2}$ stones in weight. He remained well until December 1967 when he was readmitted with jaundice.

He gave a history of the onset of a 'flu-like' illness three weeks previously, associated with anorexia and nausea but no vomiting. One week after the onset of symptoms he developed generalized itching and aching across the upper abdomen, but no colicky pain. The ileostomy effluent became light in colour and urine was mahogany coloured, and he became obviously jaundiced. He felt much iller at this stage, with marked anorexia, malaise, sweating, and rigors. On admission, on 19 December 1967, temperature was $103^{\circ} \mathrm{F}$. There was mild tenderness in the epigastrium and resistance to palpation in the right hypochondrium and epigastrium, and this was thought to be due to hepatic enlargement, although the liver edge could not be felt.

\section{Investigations}

Bile pigment and bile salts were present in the urine but no urobilinogen. Serum bilirubin was $6.1 \mathrm{mg} / 100 \mathrm{ml}$; alkaline phosphatase $54 \mathrm{KA}$ units $/ 100 \mathrm{ml}$; SGPT 170 units/ml; LDH 140 IU/litre; fasting blood glucose $95 \mathrm{mg} / 100 \mathrm{ml}$;

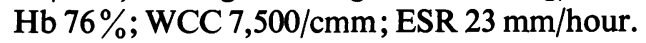

At this stage, the diagnosis was considered to be either obstructive jaundice with cholangitis, probably due to recurrent carcinoma, or possibly an infective hepatitis of a cholangitic type in view of the 'flu-like' onset, but investigations were more in keeping with an obstructive phenomenon.

Ampicillin was prescribed but by 22 December 1967 he was more ill, had developed neck rigidity and Kernig's sign was positive, and rigors were more frequent. The WCC was $13,200 / \mathrm{cmm}$. On lumbar puncture cloudy cerebrospinal fluid was obtained and, although no organisms were cultured, biochemical tests were in keeping with a bacterial menigitis, which could have been secondary to cholangitis. He responded well to a course of chloramphenicol and sulphadiazine. Jaundice, however, continued to deepen and reached $18 \mathrm{mg} / 100 \mathrm{ml}$ one week after admission.

On 24 December 1967 the patient began to pass altered blood via the ileostomy and this became more marked on 27 December 1967 when the haemoglobin was estimated at $46 \%$. Seven units of blood were transfused over the next two days and laparotomy was undertaken on 29 December 1967.

At operation the liver was deep green and enlarged three fingerbreadths below the costal margin. There was no evidence of secondary deposits. The gallbladder was large, distended and tense, and the common bile duct measured $2 \mathrm{~cm}$ in diameter. Palpation of the second part of the duodenum revealed a growth $(3 \mathrm{~cm}$ diameter) in the region of the ampulla of Vater. As the mass was not adherent to the portal vein or superior mesenteric artery, pancreatico-duodenectomy was performed. Postoperatively the patient made excellent progress and only a slight purulent discharge was noted from the drain wound. He was discharged on 22 January 1968. Follow-up has revealed no evidence of recurrence to date.

\section{Pathology (second specimen)}

A protuberant growth $(3 \mathrm{~cm}$ diameter) involved the ampulla of Vater and constricted the termination of the main pancreatic duct (Fig. 3). A tongue of growth blocked the common bile duct for a distance of $1 \mathrm{~cm}$. Histologically the tumour was a papillary adenocarcinoma of an average grade of malignancy with early invasion of the pancreas but no lymphatic involvement. Numerous sessile tumours measuring up to $1 \mathrm{~cm}$ diameter were present in the pyloric end of the stomach as well as a few very small duodenal polyps. These tumours had the histology of non-neoplastic lesions and were probably hamartomatous in nature. 
CASE 2

C.P. (III 9), born on 20 December 1946, was first seen at St. Mark's Hospital in July 1966, at the age of 19 years. Although symptom-free she was found to have several sessile adenomas on sigmoidoscopy. She was seen again in January 1967 when there was little obvious change, but one of the polyps at $19 \mathrm{~cm}$ from the anus was rather larger than the others. Colectomy and ileorectal anastomosis was performed. On the eleventh postoperative day, the patient developed mild subacute intestinal obstruction, which settled within 48 hours on a conservative regime. Fulguration of polypi in the rectum was carried out two weeks after colonic resection and the patient was discharged a few days later.

\section{Pathology}

Examination of the excised specimen revealed nearly 500 small sessile polypi which were more numerous in the left of the colon and microscopically these proved to be adenomas. There was no evidence of malignancy.

At review in January 1968 the patient was quite well and no polypi were visible in the rectum. In July 1968 she was noted to have a hard, mobile intraabdominal mass, about $10 \mathrm{~cm}$ in diameter, in the umblical region. There was keloid in the abdominal scar. A provisional diagnosis of intraabdominal fibroma was made and the patient was admitted for laparotomy.

At operation there were several fibromata in the mesentery of the small intestine, the largest being $10 \mathrm{~cm}$ in diameter. There were no intestinal adhesions. As it was quite impossible to remove these tumours, biopsy of the largest was taken and histology confirmed the diagnosis of fibroma with no signs of malignancy.

\section{CASE 3}

G.E.P. (II 7), born on 7 November 1912, was first seen at St. Mark's Hospital on 7 August 1953 with a five-year history of intermittent loose bowel actions, two or three times daily. $\mathrm{He}$ also complained of occasional bleeding with defaecation and occasional episodes of lower abdominal pain. About the time of onset of intestinal symptoms the patient noticed two hard tumours in the left frontal region and also another swelling at the left angle of the mandible, and these proved to be osteomata. He also had sebaceous cysts of the scalp and right forearm. No abnormality was detected in the abdomen, but multiple polypi were palpated in the rectum and sigmoidoscopy revealed polypi of variable size. There were large polypid masses at $9 \mathrm{~cm}$ and $17 \mathrm{~cm}$ from the anus and several other smaller polyps from $6 \mathrm{~cm}$ upwards. Biopsies of the mass at $9 \mathrm{~cm}$ showed histological features of a villous papilloma and biopsies of the mass at $17 \mathrm{~cm}$ showed a papillary adenoma. No evidence of malignancy was demonstrated in any of these sections.

On 25 August 1952 colectomy was carried?

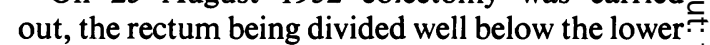
of the two large masses. A low ileorectal ana- $\overrightarrow{\vec{c}}$ stomosis was effected. Progress was satisfactoryfor three days and then the patient developed $\frac{\bar{C}}{\square}$ intestinal obstruction and, on the fifth post $-\frac{\overline{\bar{c}}}{\text {. }}$ operative day, laparotomy was necessary to $\widetilde{\Phi}$ free adhesions and kinking just above the level $\stackrel{\circ}{\circ}$ of the ileorectal anastomosis. Thereafter, he ${ }^{\infty}$ made steady progress, although for a time he $\vec{O}$ had urgency of defaecation, sometimes leading $\overrightarrow{\vec{H}}$ to incontinence because of the very small rectal $\stackrel{\omega}{\omega}$ reservoir.

\section{Pathology}

The operation specimen showed numerous polyps scattered throughout the colon which $\mathbb{\omega}^{N}$ were smaller and less numerous on the right sideo than on the left. One tumour in the recto-sigmoid region was definitely malignant but the carcino- $\rightarrow$

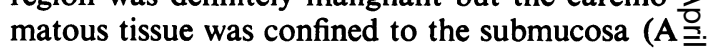
case).

The remaining polypi in the rectum were subsequently fulgurated on a number of occasions and also dilatation of the anastomosis was performed because of a minor degree of stenosis.

The patient remained very well and was free of all symptoms when reviewed in May 1969.

\section{CASE 4}

G.I.P. (II 8), born on 3 August 1915, first attended St. Mark's Hospital on 20 March $1954 \stackrel{-}{-}$ because his brother was found to have polyposis coli. He stated that he always had two or three loose motions per day and occasional rectal 3 bleeding. In adolescence he had had several $\delta$ lumps on the limbs and trunk, presumably sebaceous cysts.

When first seen at St. Mark's Hospital no abnormality was detected on abdominal examin-o ation, but sigmoidoscopy revealed multiple sessile and polypoid lesions of the rectum. O Barium enema showed that polyposis involved ${ }^{N}$ the colon at least as far proximally as the transverse colon.

The patient was admitted on two occasionsco for fulguration of rectal polypi before colectomy $\mathbb{\Phi}$ and ileorectal anastomosis, in June 1954, after $\stackrel{?}{?}$ which he made an uneventful recovery.

Pathological examination of the resected $\stackrel{\vec{\Phi}}{\circ}$ specimen revealed many polyps throughout $\stackrel{\odot}{\odot}$ the colon but particularly in the left side. In $\stackrel{\mathbb{Q}}{\mathscr{Q}}$ this region the polyps were larger and hado acquired stalks up to half an inch in length. Microscopy confirmed the adenomatous nature of these polypi. There was no evidence of malignancy.

During the subsequent 15 years of follow up, the patient was readmitted on five occasions for fulguration of rectal adenomas. A sebaceous 
cyst was removed from the right shoulder in December 1963.

\section{Discussion}

The occurrence of extracolonic tumours in association with familial polyposis has been well documented on many occasions. The sites of origin, the nature of the tumours, and the point in time when they make their appearance do not closely follow any particular pattern. Almost any tissue in the body can be involved to a greater or lesser degree, although such tumours seem to arise more commonly in the head, abdomen, and the extremities. Virtually no associated chest lesion has ever been described. The severity of the extracolonic abnormalities does not appear to be closely related to the number or size of the polypi in the large bowel or to an early onset in an individual.

\section{PERIAMPULLARY CARCINOMA}

Carcinoma in the region of the ampulla of Vater in patients with Gardner's syndrome is probably not just coincidental. Cabot (1935) reported a patient with polyposis coli who had multiple bony tumours of the cranium and mandible as well as soft tissue tumours over the entire body. The patient died at the age of 36 years, and at necropsy he was found to have a carcinoma of the ampulla of Vater, in addition to multiple polyps in the duodenum, jejunum, ileum, and colon. MacDonald, Davis, Crago, and Berk (1967) reported two cases of periampullary carcinoma associated with Gardner's syndrome. In addition, one of these cases had two papillary adenomas in the duodenum, neither of which was adjacent to the ampulla, and the other had an adrenal adenoma. Recently, Capps, Lewis, and Gazzaniga (1968) reported a case of triple primary carcinoma affecting the colon, the ampulla of Vater, and the urinary bladder in a patient with familial polyposis coli, but without other stigmata of Gardner's syndrome. McFarland, Scheetz, and Knisley (1968) have also reported the association of periampullary carcinoma in a case of polyposis with other stigmata of Gardner's syndrome.

The finding in case 1 of a carcinoma of the ampulla of Vater, causing intestinal bleeding, in addition to the sequence of common bile duct obstruction, cholangitis, bacteraemia, and meningitis, was of considerable interest. The presumptive diagnosis of secondary carcinoma, two years after resection of a carcinoma of the transverse colon, did not fit the clinical picture completely unless there was erosion into the intestinal tract to cause bleeding as well as the sequel of common bile duct obstruction. It was of paramount importance in this patient that the cause of the jaundice was fully pursued rather than assuming that it was due to recurrent growth, as the lesion discovered was removable.

Finally, it may be added that two other patients who were possible examples of Gardner's syndrome underwent colectomy for polyposis at St. Mark's Hospital. One of these subsequently developed carcinoma of the duodenum and the other developed carcinoma of the pancreas.

In view of these reports it is suggested that before colectomy and ileorectal anastomosis in polyposis cases with Gardner's syndrome the upper intestinal tract should be radiographed and that at operation the duodenum should be carefully palpated in a search for polyps or a carcinoma of the periampullary region, especially in older patients. During the follow-up period, if symptoms warrant it, investigations of the upper intestinal tract should be performed.

SMALL INTESTINAL ADENOMAS AND DUODENAL HAMARTOMAS

Adenomata of the small intestine have been reported in association with polyposis(McKittrick et al 1935; Pollack and Swinton, 1955; Gumpeland Carballo, 1956). Two patients in the series of Thomas, Watne, Johnson, Roth, and Zimmerman (1968) had polypoid masses in the terminal ileum, but these were found to be hypertrophied lymphoid tissue on microscopy. Thomford and Greenberger (1968) also noted lymphoid polyps in the ileum in a polyposis patient who had osteochondromata of the mandible. The finding in case 1 of duodenal and gastric polypi of a hamartomatous variety is emphasized, as this type of polyp does not appear to have been described before in patients with polyposis coli although other pathological varieties have been noted in the gastroduodenal region.

\section{MESODERMAL TUMOURS}

Fibromata may be found superficially (Devic and Bussy, 1912; Gardner and Richards, 1953) or in the mesentery of the small or large intestine (Pugh and Nesselrod, 1945; O'Brien and Wels, 1955; Gumpel and Carballo, 1956; Shepherd, 1958). Fibromata may also be encountered in or near the scar after colectomy (O'Brien and Wels, 1955; Shepherd, 1958).

One of the cases reported here (case 2) developed extensive mesenteric and retroperitoneal fibromata within one year of colectomy and ileorectal anastomosis. At laparotomy these tumours were also so extensive that removal was out of the question. This tendency to develop intraabdominal fibrous tumours postoperatively raises questions of management in cases of polyposis coli. It would seem that such tumours tend to appear after operation and that surgical trauma is a precipitating factor in their causation in patients predisposed to them. In 


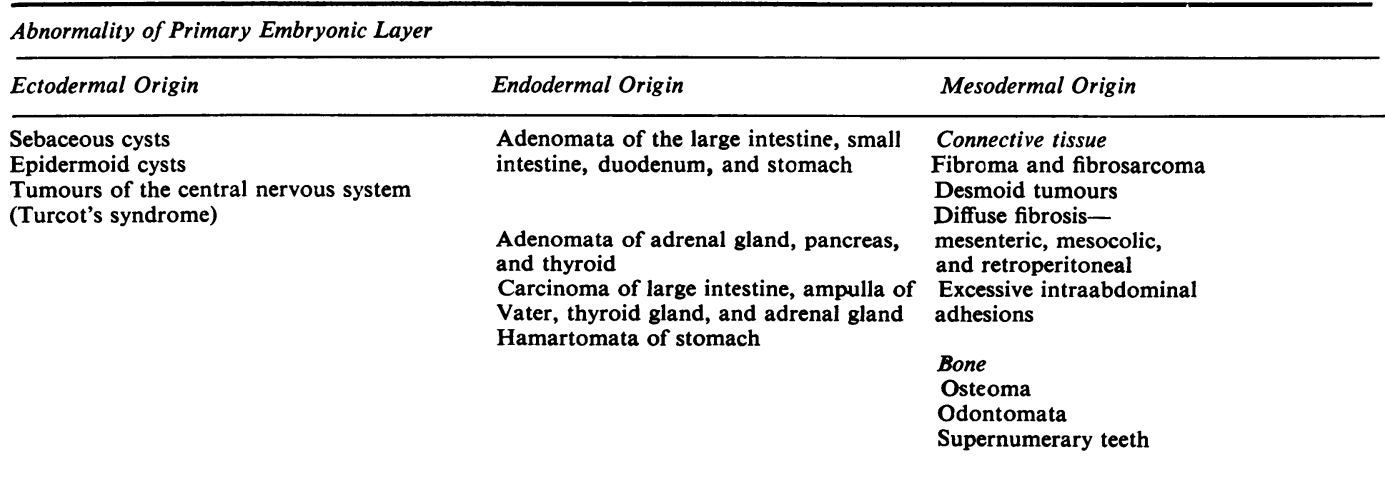

Table Abnormalities grouped according to derangement in primary embryonic layers

view of this definite trend towards abnormal fibrous growth within the abdomen in patients from a Gardner's family, perhaps surgery should be delayed as long as feasible. Obviously all affected members will require surgery sooner or later as the risk of colon cancer remains. It might be wise to delay surgery for some years in young people who are known to be members of a Gardner's family and who, therefore, might develop mesenteric fibromata or possibly other dangerous lesions, as there does not appear to be any evidence that carcinoma develops at an earlier age in patients with Gardner's syndrome than in other patients with polyposis coli.

In those cases in which intraabdominal mesodermal growths do occur, the prognosis may be reasonable. Other patients with Gardner's syndrome, treated at St. Mark's Hospital, have had large irremovable fibromata, yet have remained otherwise very well for many years.

Intraabdominal tumours may cause pain and obstruction within two or three years of colectomy for polyposis. They are not infrequently mistaken for malignant secondaries. Simpson, Harrison, and Mayo (1964) studied the association of familial polyposis of the colon with mesenteric fibromatosis in 15 cases from the literature and seven cases seen at the Mayo Clinic. In these cases, the mesenteric lesion was a benign fibrous tumour with infiltrative tendencies, which usually appeared after intestinal surgery, but, in spite of the alarming appearances, the prognosis was favourable in most cases. Some of the patients developed severe intraperitoneal adhesions and obstruction.

Fibrosarcoma has been reported on a few occasions (Miller and Sweet, 1937; Gumpel and Carballo, 1956; Collins, 1959). Some authors (Weary, Linthicum, Cawley, Coleman, and Graham, 1964; Jones and Cornell, 1966) suggest that so-called fibrosarcomata may, in actual fact, be desmoid tumours, since up until the time of their reports there was no evidence of metastases in any of the reported cases, and possibly some of these are examples of mis- diagnosis. However, Thomas et al (1968) in-

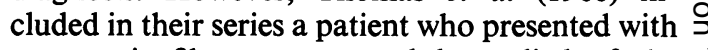
mesenteric fibrosarcoma and later died of the effects of infiltration of the wall of the small intestine.

Desmoid tumours may appear in or near the $\overrightarrow{\vec{\varphi}}$ scar after colectomy (O'Brien and Wels, 1955; Hughes and Hueston, 1960). Seventeen of 211 polyposis patients reported by Smith (1958) had one or more abnormalities of Gardner's syndrome, and six out of 17 had histologically confirmed desmoid tumours associated with the abdominal scars. Two other patients had nodules in the scars which were never biopsied, but at least one of these was almost certainly a desmoid. An incidence of $3.5 \%$ in Smith's collected series contrasts with an incidence of only $0.03 \%$ in a study of 50,346 admissions to the Memorial Hospital, reported by Pack and Ehrlich (1944).

In 112 cases of polyposis coli operated on at St. Mark's Hospital, desmoid tumours were noted in six patients (Lockhart-Mummery, 1967). Five of these had previous surgery. Two ? patients with desmoid tumours of the abdominal wall also had multiple fibromata of the small bowel mesentery and retroperitoneal tissues. In addition to colectomy and ileorectal anastom- $N$ osis, one of these patients had desmoid tumours of స్心 the anterior abdominal wall excised on three occasions within a period of 18 months. Two years later, in 1961, a further operation was carried out to remove the superficial part of a large mass $\stackrel{\oplus}{-}$ in the suprapubic region, as complete excision was impossible. Since that time there has been no further enlargement of the lesion and the patient remains generally well.

In addition to the discrete tumour masses in the form of fibromata or desmoid tumours, the excessive fibrous reaction may take a more diffuse form, infiltrating the mesentery or mesocolon or retroperitoneal tissues (Simpson et al, 1964).Thomas et al (1968) observed that this manifestation of excessive fibrous tissue proliferation is sometimes seen in patients with familial 
polyposis without any other stigmata of Gardner's syndrome.

Kaplan (1961) observed a high incidence of postoperative intestinal obstruction due to fibrous bands in polyposis cases. This was confirmed in a report from St. Mark's Hospital of a series by Lockhart-Mummery (1967) in which $20 \%$ of the polyposis patients who had abdominal operations subsequently required a further operation for intestinal obstruction. This is exemplified in this communication by case 3 in whom laparotomy for adhesions was carried out on the fifth postoperative day.

\section{ECTODERMAL TUMOURS}

Oldfield (1954) described the association of multiple sebaceous cysts and polyposis coli in one family group in which three members had both conditions and three other members had multiple sebaceous cysts but no colonic disease. Both conditions appeared to be inherited on the basis of a dominant gene. Smith (1958) recorded the association of familial polyposis and sebaceous cysts in at least four of his cases.

Tumours of neuroectoderm have been described in association with polyposis coli by Turcot, Despres, and St. Pierre (1959) in two members of one family, one of whom had a frontal glioblastoma and the other a medulloblastoma. Unfortunately, little information is available on one of the cases in this present pedigree but enough has been obtained to support strongly a diagnosis of Turcot's syndrome.

\section{GENETICS}

Gardner and Richards (1953) suggested that a single dominant gene was responsible for all the lesions seen in the syndrome and most subsequent workers concur with this concept of a pleiotrophic gene. McKusick (1962) held that there is a single gene which is responsible for Gardner's syndrome and that this is different from the gene responsible for simple familial polyposis. On the other hand, Smith (1958) submitted that the variation in penetrance of the gene could explain not only the presence or absence but also the degree to which any of the features exists.

In conclusion we have attempted to classify the increasing variety of tumours that have been reported in patients with familial polyposis but it is not yet clear whether some of these are actually associated with the condition or whether they are only incidental findings. All embryonic layers may be involved and it may be found helpful to group the abnormalities according to derangement in the primary embryonic layers (Table).

Some of the lesions, as well as other varieties not listed, have been recorded on only a few occasions and only the passage of time, with additional cases and larger series, will clarify whether, in actual fact, the association is an integral part of the syndrome.
We wish to thank Dr B. C. Morson for his help in the pathological diagnoses and $\mathrm{Mr}$ N. Mackie for providing the photographs.

\section{References}

Capps, W. F., Jr., Lewis, M. I., and Gazzaniga, D. A. (1968). Carcinoma of the colon, ampulla of Vater and urinary bladder associated with familial multiple polyposis. Dis. Colon Rect., 11, 298-305.

Chargelaigne, A. (1859). Des Polypes du Rectum. Thesis, Paris.

Collins, D.C. (1959). The frequent association of other body tumors with familial polyposis. Amer.J. Gastroent., 31, 376-381.

Devic, A., and Bussy, N. M. (1912). Un cas de polypose adénomateuse généralisée à tout l'intestin. Arch. Mal. Appar. dig.,

Gardner, E. J. (1962). Follow-up study of a family group exhibiting dominant inheritance for a syndrome including intestinal polyps, osteomas, fibromas and epidermal cysts. Amer. J. hum. Genet., 14, 376-390

Gardner, E. J., and Richards, R. C. (1953). Multiple cutaneous and subcutaneous lesions occurring simultaneously with hereditary polyposis and osteomatosis. Amer. I. hum. Genet., 5, 139-147.

Gumpel, R. C., and Carballo, J. D. (1956). A new concept of familial adenomatosis. Ann. intern. Med., 45, 1045-1058.

Handford, H. (1890). Disseminated polypi of the large intestine becoming malignant. Trans. path. Soc. Lond., 41, 133-137.

Hughes, E. S. R., and Hueston, J. T. (1960). Desmoid tumour in familial polyposis of the colon: report of a case. Aust. N.Z. J. Surg., 30, 131-139.

Jones, E. L., and Cornell, W. P. (1966). Gardner's syndrome. Review of the literature and report on a family. Arch. Surg., 92, 287-300.

Kaplan, B. J. (1961). Gardner's syndrome: heredo-familial adenomatosis associated with 'soft and hard' fibrous tumors and epidermoid cysts. Dis. Colon Rect., 4, 252-262.

Lockhart-Mummery, H. E. (1967). Intestinal polyposis: the present position. Proc. roy. Soc. Med., 60, 381-388.

MacDonald, J. M., Davis, W. C., Crago, H. R., and Berk, A. D. (1967). Gardner's syndrome and peri-ampullary malignancy. Amer.J. Surg., 113, 425-430.

McFarland, P. H., Jr., Scheetz, W. L., and Knisley, R. E. (1968). Gardner's syndrome: report of two families. J. oral Surg., 26, 632-638.

McKittrick, L.S., et al. (1935). Case record of the Massachusetts General Hospital, Case No. 21061. New Engl.J. Med., 212,
263-267.

McKusick, V. A. (1962). Genetic factors in intestinal poloposis. J. Amer. med. Ass., 182, 271-277.

Miller, R. H., and Sweet, R. H. (1937). Multiple polyposis of the colon: a familial disease. Ann. Surg., 105, $511-515$.

O'Brien, J. P., and Wels, P. (1955). The synchronous occurrence of benign fibrous neoplasia in hereditary adenosis of the colon and rectum. N.Y. St.J. Med., 55, 1877-1880.

Oldfield, M. C. (1954). The association of familial polyposis of the colon with multiple sebaceous cysts. Brit. J. Surg., 41, 534-541.

Pack, G. T., and Ehrlich, H. E. (1944). Neoplasms of the anterior abdominal wall with special consideration of desmoid tumors. Experience with 391 cases and a collective review of the literature. Int. Abstr. Surg., 79, 177-198.

Pollack, J. L., and Swinton, N. W. (1955). Congenital polyposis of the colon with extension to the small intestine and stomach. Lahey Clin. Bull., 9, 174-179.

Pugh, H. L., and Nesselrod, J. P. (1945). Multiple polypoid disease of the colon and rectum. Ann. Surg., 121, 88-99.

Shepherd, J. A. (1958). Familial polyposis of the colon with associated connective tissue tumours. J. roy. Coll. Surg. Edinburgh., 4, 31-38.

Simpson, R. D., Harrison, E. G., Jr., and Mayo, C. W. (1964). Mesenteric fibromatosis in familial polyposis; a variant of Gardner's syndrome. Cancer (Philad.), 17, 526-534.

Smith, W. G. (1958). Multiple polyposis, Gardner's syndrome and desmoid tumors. Dis. Colon. Rect., 1, 323-332.

Thomas, K. E., Watne, A. L., Johnson, J. G., Roth, E., and Zimmermann, B. (1968). Natural history of Gardner's syndrome. Amer. J. Surg., 115, 218-226.

Thomford, N. R., and Greenberger, N. J. (1968). Lymphoid polyps of the ileum associated with Gardner's syndrome. Arch. Surg., 96, 289-291.

Turcot, J., Després, J. P., and St. Pierre, F. (1959). Malignant tumors of the central nervous system associated with familial polyposis of the colon. Dis. Colon. Rect., 2, 465-468.

Weary, P. E., Linthicum, A., Cawley, E. P., Coleman, C. C., Jr., and Graham, G. F. (1964). Gardner's syndrome. A family group study and review. Arch. Derm., 90, 20-30. 